\title{
Erratum to: A High-Resolution LC-MS/MS Method for the Quantitative Determination of Artemether and Its Metabolite Dihydroartemisinin in Human Plasma and Its Application to Pharmacokinetic Studies
}

\author{
Fazli Khuda $^{1} \cdot$ Zafar Iqbal $^{1} \cdot$ Yasar Shah $^{2} \cdot$ Muhammad Abbas $^{2} \cdot$ Zakiullah $^{1}$. \\ Muhammad Hassan ${ }^{1}$
}

Published online: 6 April 2016

(C) Springer-Verlag Berlin Heidelberg 2016

\section{Erratum to: Chromatographia DOI 10.1007/s10337-016-3064-6}

The publisher would like to call the reader's attention to the fact that unfortunately the Compliance with ethical standards section was not correctly displayed.

The correct Compliance with ethical standards section is given below:

\section{Conflict of interest}

There are no competing interests to declare.

\section{Ethical approval}

The clinical trials were conducted according to the guidelines of "World Medical Associations, Declaration of
Helsinki ethical principles for medical research involving human subjects" and were approved by the Ethics Committee of the Department of Pharmacy, University of Peshawar (Trial number 02/EC-12/Pharm).

\section{Informed consent}

A written informed consent was obtained from all the participants enrolled in the study.

Our sincere apologies to the authors.

The online version of the original article can be found under doi:10.1007/s10337-016-3064-6.

Fazli Khuda

fazlikhuda2012@upesh.edu.pk

1 Department of Pharmacy, University of Peshawar, Peshawar, Pakistan

2 Department of Pharmacy, Abdul Wali Khan University, Mardan, Pakistan 